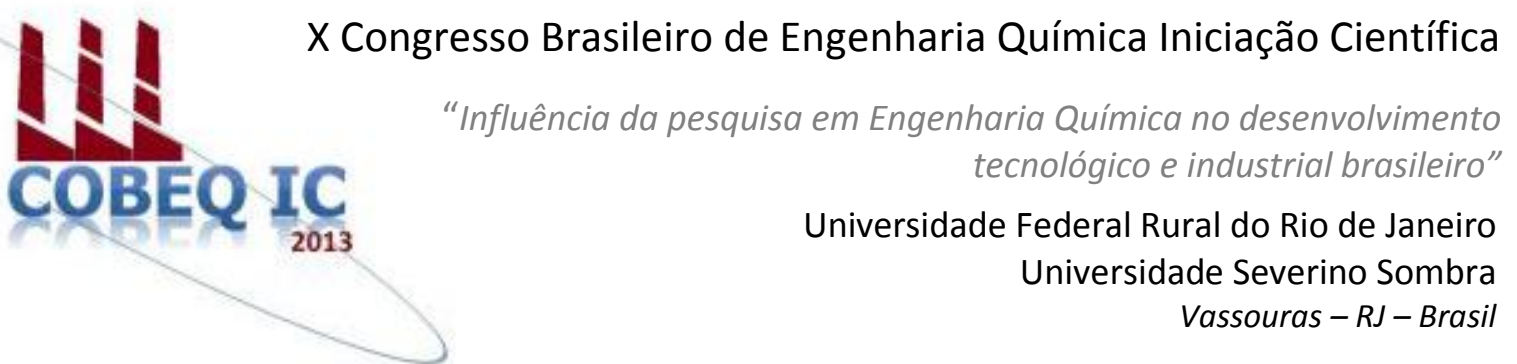

\title{
ESTUDO DA VIABILIDADE DE Lactobacillus acidophilus NA PRODUÇÃO DE CHOCOLATE PROBIÓTICO E CARACTERÍSTICAS DO PRODUTO
}

\author{
A. A. Mazetti ${ }^{1}$; T. M. A. Pinheiro ${ }^{2}$; I. M. V. Barbosa $^{3}$; R. C. Teixeira ${ }^{4}$; V. L. Cardoso ${ }^{5} e^{2}$ \\ U. Coutinho Filho ${ }^{6}$ \\ (1) e (3) Graduação em Engenharia Química da UFU; (2) e (4) Programa de Pós-graduação em \\ Engenharia Química da UFU; ${ }^{(5)}$ e (6) Faculdade de Engenharia Química - FEQUI/UFU;
}

Faculdade de Engenharia Química - Universidade Federal de Uberlândia - UFU, Av. João Naves de Ávila, 2121, Bloco 1K, Campus Santa Mônica, Uberlândia - MG, CEP 38408 e-mail: $\underline{\text { ucfilho@feq.ufu.br }}$

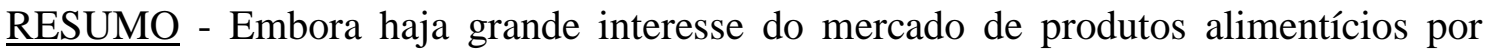
produtos inovadores, como por exemplo, o chocolate com adição de probióticos, ainda há poucos trabalhos na literatura sobre o tema. Diante deste fato o presente trabalho foi realizado com o objetivo de preparar chocolates probióticos e avaliar a: a) influência do tipo de chocolate (chocolate ao leite, chocolate meio amargo e chocolate amargo) na sobrevida das células; b) substituição de um meio de cultura tradicional otimizado para lactobacilos (meio MRS) por outro que tenha como característica baixo custo e que possa ser usado na alimentação humana; c) aceitação do chocolate preparado. Foram realizadas fermentações submersas para produção de células probióticas nos meios MRS e meio contendo levedura de cerveja e glicose (meio de baixo custo adequado para alimentação humana) que foram centrifugadas à $8000 \mathrm{rpm}$ e adicionadas a massa de chocolate. Os resultados indicaram que: a) o chocolate ao leite foi favoreceu a maior viabilidade celular; b) o meio otimizado apresentou maior concentração final de células, embora os dois meios testados foram adequados para o crescimento celular; c) o meio testado em substituição ao meio tradicional (meio MRS) foi o que forneceu maior viabilidade das células; c) o chocolate probiótico possui boa aceitação no que se refere ao sabor do mesmo.
\end{abstract}

Palavras chave: chocolate, probiótico, Lactobacillus acidophilus

\section{INTRODUÇÃO}

Probióticos são microorganismos vivos que quando administrados em quantidades adequadas exercem efeitos benéficos na saúde do hospedeiro (MENG et al., 2008). São considerados alimentos funcionais e podem ser encontrados em produtos como sucos de frutas, suplementos em pó e em preparações lácteas.

Esses micro-organismos atuam no trato intestinal promovendo benefícios como resistência gastrintestinal à colonização por patógenos, promoção da digestão da lactose

\footnotetext{
(1) Bolsista do Programa de Educação Tutorial do MEC; ${ }^{(3)}$ Bolsista de iniciação científica do CNPq, discente do curso
} de Engenharia Química; ${ }^{(4)}$ SENAI (Serviço Nacional de Aprendizagem Industrial) - Uberlândia; 
em indivíduos intolerantes a esse açúcar, estimulação do sistema imune, alívio da constipação, entre outros (CHAN e ZHANG, 2005).

Dentre os micro-organismos probióticos destacam-se as bactérias lácticas, em especial as bactérias do gênero Lactobacillus sp., que são capazes de se desenvolver em condições e ambientes diversos.

O chocolate é um alimento nutritivo, energético, de fácil digestão e metabolização que apresenta mais de trezentos componentes diferentes, que possuem efeitos benéficos no metabolismo, como os efeitos antioxidante e anti-inflamatório, a capacidade de melhorar o humor e a atividade mental e até de prevenir doenças cardíacas (BATISTA, 2008).

Apesar da variedade de produtos lácteos, o mercado ainda busca por inovações de produtos que sejam capazes de garantir a eficácia das bactérias durante a vida útil do produto, pois a eficácia dos probióticos é influenciada por diversos fatores como a viabilidade celular dos microrganismos no produto original, ação dos fluidos biológicos associados à digestão do produto, transformações associadas ao processamento dos probióticos, condições de armazenamento, estresse osmótico, oscilações de temperatura e o processo natural de morte celular (CHAN e ZANG 2005).

O processo de morte celular seja associado a fatores externos ou ao envelhecimento das células pode ser influenciado pela forma que o probiótico é preparado, e dentre as formas de reduzir a perda de viabilidade, destaca-se a imobilização como um método capaz de reduzir efeitos geradores de estresse físico e bioquímico para a célula. $\mathrm{Na}$ imobilização o suporte dificulta a ação direta dos efeitos estressantes na estrutura proteica e nas membranas celulares, ao mesmo tempo em que protege as células da contaminação por fungos e bactérias indesejáveis (OUYANG et al, 2004; LEE, HEO, 2000).

Embora seja grande a aceitação dos chocolates e os chocolates com probióticos representem uma inovação no mercado de chocolates, ainda existem poucos estudos que descrevem estes alimentos probióticos. Dessa forma, no presente trabalho é apresentada uma comparação entre probióticos imobilizados preparados com chocolate com a finalidade de compreender melhor $\mathrm{o}$ efeito do meio fermentativo e das características do produto na viabilidade das células de Lactobacillus acidophilus. Buscou-se avaliar a substituição de constituintes do meio otimizado para lactobacilos (MRS) por componentes de baixo custo e aceitáveis para o consumo humano, de forma a favorecer o uso deste chocolate em testes de análise sensorial.

\section{MATERIAIS E MÉTODOS}

\section{Micro-organismos e meios de cultura}

Foram realizadas fermentações submersas de Lactobacillus acidophilus LA-5 com concentração celular inicial de $10^{6}$ células/L em Erlenmeyers de $250 \mathrm{~mL}$, contendo $100 \mathrm{~mL}$ de meio, com agitação de $300 \mathrm{rpm}$ em incubador rotativo a $30^{\circ} \mathrm{C}$ por $48 \mathrm{~h}$ em meios de cultura denominados M1, M2 e M3, cujas composições estão especificadas na Tabela 1. Para cada fermentação foi realizada a medida da concentração celular para os tempos de fermentação de $2,4,6,8,10,12$, 16,24 e 48 horas.

\section{Tabela 1 - Composição dos meios de cultura}

\begin{tabular}{|c|c|}
\hline Meio & Composição do meio \\
\hline & $\begin{array}{c}\text { Glicose }(20 \mathrm{~g} / \mathrm{L}) \text {, peptona de caseína } \\
(10 \mathrm{~g} / \mathrm{L}) \text {, extrato de carne }(10 \mathrm{~g} / \mathrm{L}), \\
\text { extrato de levedura }(5 \mathrm{~g} / \mathrm{L}), \text { tween } 80 \\
(1 \mathrm{~g} / \mathrm{L}), \text { fosfato de potássio dibásico } \\
(2 \mathrm{~g} / \mathrm{L}), \text { acetato de sódio }(5 \mathrm{~g} / \mathrm{L}), \\
\text { M1 } \\
\text { citrato de amônio }(2 \mathrm{~g} / \mathrm{L}), \text { sulfato de } \\
\text { manganês }(0,05 \mathrm{~g} / \mathrm{L}), \text { sulfato de } \\
\text { magnésio }(0,2 \mathrm{~g} / \mathrm{L})\end{array}$ \\
\hline M2 & $\begin{array}{c}\text { Glicose }(20 \mathrm{~g} / \mathrm{L}), \text { levedo de cerveja }(6 \\
\mathrm{g} / \mathrm{L}), \text { extrato de Camelia sinensis } \\
25 \%(\mathrm{v} / \mathrm{v}) *\end{array}$ \\
\hline M3 & $\begin{array}{c}\text { Glicose }(20 \mathrm{~g} / \mathrm{L}), \text { levedo de cerveja }( \\
6 \mathrm{~g} / \mathrm{L})\end{array}$ \\
\hline
\end{tabular}

* Nota: preparado com $10 \mathrm{~g}$ de folhas secas para 500 $\mathrm{mL}$ de água 


\section{Preparação probióticas \\ das \\ formulações}

Para a preparação dos chocolates utilizou-se células centrifugadas a $10{ }^{\circ} \mathrm{C}$ e $8000 \mathrm{rpm}$ por $10 \mathrm{~min}$ obtidas da fermentação de $L$. acidophilus utilizando os meios e as condições descritos no item 1. As células obtidas da fermentação do meio de cultura M1 (MRS) foram adicionadas a diferentes tipos de chocolate, cujas composições estão especificadas da Tabela 2.

Tabela 2 - Composição das preparações de chocolate

\begin{tabular}{|c|c|}
\hline Formulação & $\begin{array}{c}\text { Composição da formulação } \\
\text { (\% em massa) }\end{array}$ \\
\hline $\mathrm{Ch} 1$ & $\begin{array}{c}\text { chocolate ao leite } 75 \% \mathrm{e} \\
\text { células de lactobacilos } 25 \%\end{array}$ \\
\hline $\mathrm{Ch} 2$ & $\begin{array}{c}\text { chocolate meio amargo } 75 \% \mathrm{e} \\
\text { células de lactobacilos } 25 \%\end{array}$ \\
\hline $\mathrm{Ch} 3$ & $\begin{array}{c}\text { chocolate amargo } 75 \% \mathrm{e} \\
\text { células de lactobacilos } 25 \%\end{array}$ \\
\hline
\end{tabular}

Nota: Teor de sólidos de cacau (\% em massa): chocolate ao leite, 25\%; meio amargo, 53\%; amargo, $75 \%$.

Num primeiro momento, realizou-se a análises dos meios fermentados após 24h de fermentação a fim de avaliar a concentração de células (utilizando-se um espectrofotômetro para medir a absorbância da amostra a $600 \mathrm{~nm}$, usando-se uma curva de calibração da concentração em função da absorbância) para cada um dos meios. Isso foi feito de forma a possibilitar o uso de um volume de meio fermentado capaz de gerar a concentração celular de interesse.

Para a preparação dos chocolates adicionou-se as células probióticas a uma massa de chocolate derretido. As formulações foram acondicionadas em formas e após resfriadas, foram embrulhadas em papel alumínio e mantidas a $25 \pm 2{ }^{\circ} \mathrm{C}$.

A avaliação da viabilidade das células de lactobacilos foi feita em termos de sobrevida obtida a partir do modelo não paramétrico de Kaplain-Meier ajustado em linguagem $\mathrm{R}$ para os períodos de $4,9,14,18,23$ e 28 dias de armazenamento do produto.

\section{Quantificação da concentração celular de Lactobacillus acidophillus LA-5}

A contagem das células em todos os experimentos, tanto nas avaliações da viabilidade das células no chocolate quanto na construção das curvas de padronização (absorbância em função da concentração), foi feita por plaqueamento em profundidade em meio Agar MRS com a contagem de $48 \mathrm{~h}$ de incubação à temperatura de $25^{\circ} \mathrm{C}$. Antes da contagem, cada amostra de chocolate era dissolvida em leite em pó desnatado reconstituído $(10 \% \mathrm{p} / \mathrm{v})$ na temperatura de $45^{\circ} \mathrm{C}$ que era usada no plaqueamento.

\section{RESULTADOS E DISCUSSÕES}

A Figura 1 apresenta o resultado da contagem de células fermentadas em meio M1 (MRS) adicionadas às diferentes formulações de chocolate (Tabela 2) armazenadas por um período de 7 a 28 dias.

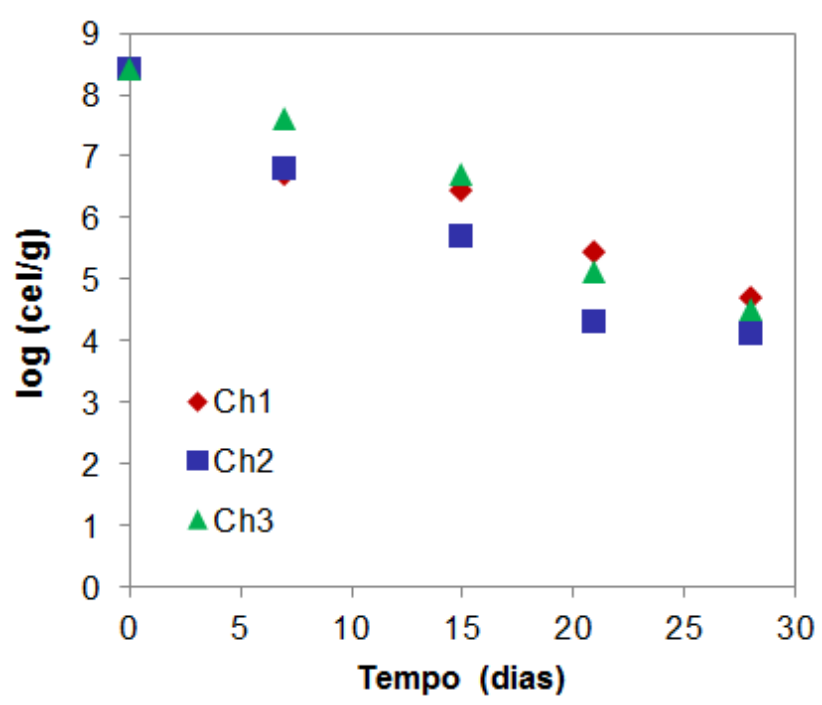

\section{Figura 1 - Estabilidade das formulações de chocolate (Ch1, Ch2, Ch3)}

A partir dos dados é possível observar que a formulação de chocolate ao leite (Ch1) foi a mais estável, dado que esta preparação foi a que apresentou maior número final de células viáveis. Desse modo, esta foi a formulação escolhida para a avaliação do meio 
de fermentação (avaliação do meio de fermentação).

As concentrações celulares obtidas nas fermentações nos meios M1, M2 e M3 e que foram adicionadas ao chocolate ao leite (formulação Ch1) são mostradas na Figura 2.

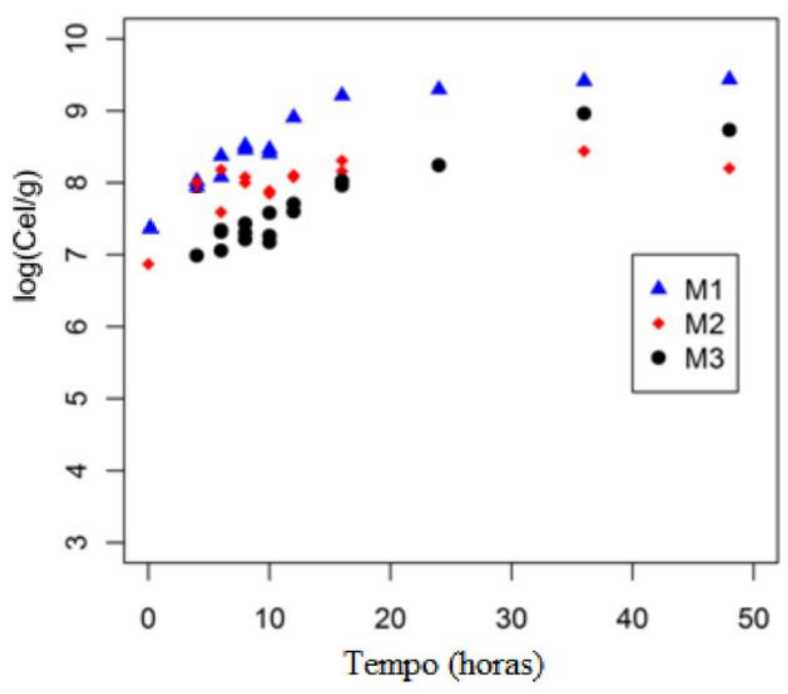

Figura 2 - Crescimento celular nos meios fermentativos M1, M2 e M3

A comparação entre o meio de referência M1 e o meio M2 (Figura 2) mostra que nas condições testadas não foi possível melhorar a viabilidade das células pela ação antioxidante dos compostos fenólicos de $C$. sinensis, pois a ação destes compostos no meio M2 na concentração utilizada reduziu tanto o crescimento quanto a viabilidade celular. A comparação entre o meio de referência M1 e o meio M3 (Figura 2) mostra que embora o meio M3 gere menor crescimento celular o mesmo não desfavorece a fermentação, o que significa que o mesmo pode ser usado no processo.

Embora o meio M1 seja o mais favorável para o crescimento das células o mesmo não é adequado para o uso em alimentos. Dado que o meio M3 foi mais adequado que M2 para o crescimento das células em chocolate, esse foi utilizado no estudo de sobrevida de células (Figura 3).

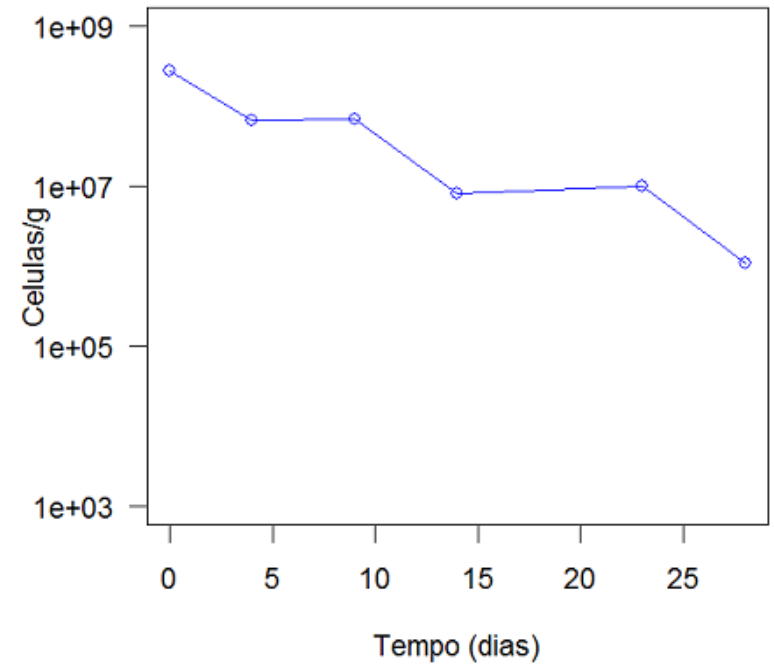

Figura 3 - Sobrevida de células de L. acidophilus em meio M3 (glicose com levedo de cerveja)

Pode-se observar neste estudo que o chocolate gerado com M2 apresenta manutenção de $10^{6}$ células/g para tempos superiores a 20 dias de armazenamento.

As Figuras 4 e 5 apresentam os resultados dos ajuste da análise de sobrevida das células e de função densidade realizadas pelo modelo de Weibull:

$$
S(t)=\alpha t^{\beta}
$$

onde os valores obtidos para parâmetros $\alpha$ e $\beta$ e a correlação foram: $\alpha=1,44$; $\beta=9,41$ e r $^{2}=0,86$.

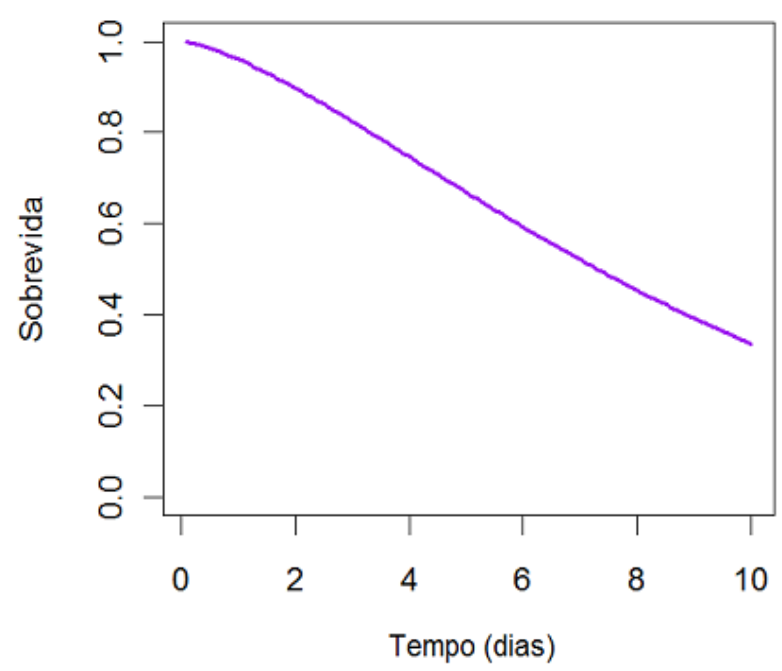

Figura 3 - Sobrevida de células de L. acidophilus em meio M3 (glicose com levedo de cerveja) 


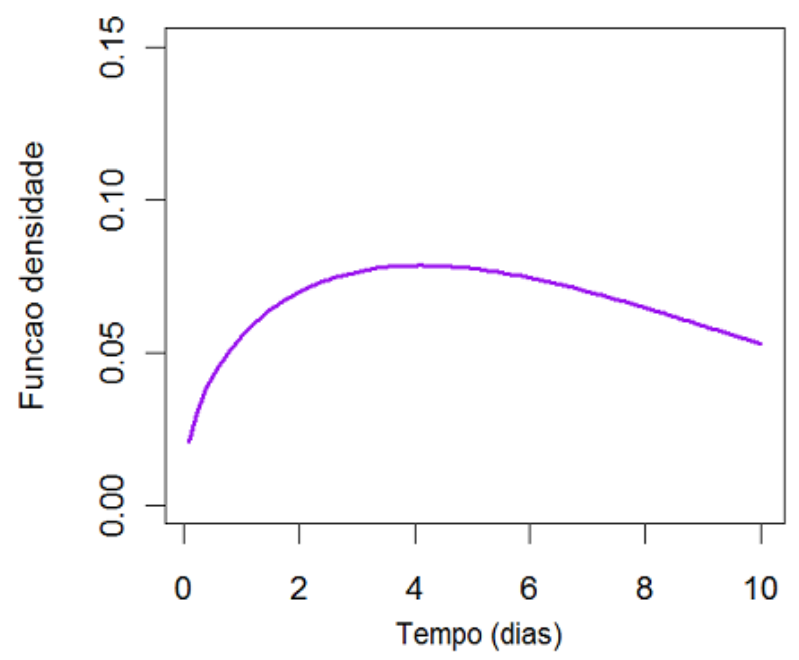

Figura 4 - Função densidade de células de L. acidophilus em meio M3 (glicose com levedo de cerveja)

A avaliação dos resultados previstos pelo modelo sugere que a grande quantidade de células é que mantém população de células superior a $10^{6}$ célula/g para o tempo de armazenamento de até 5 dias (Figura 3 ) e que a maior parte das mortes celulares ocorre entre 2 e 6 dias de armazenamento (Figura 4).

\section{CONCLUSÕES}

A partir dos resultados obtidos é possível inferir que a composição do meio representa um fator que influi diretamente na estabilidade das células adicionadas ao chocolates. Com relação ao tipo de chocolate, foi possível verificar que o maior teor de lipídeo em conjunto com o maior teor de sólidos de cacau (Ch3) não geram de forma isolada a situação de melhor viabilidade para células, ou seja, o teor de flavonoides e outros compostos do chocolate em associação a fração lipídica desempenham função importante na viabilidade celular.

Com relação ao meio de fermentação das células foi possível constatar que a composição e condições que favorecem maior crescimento celular não favorecem necessariamente a maior viabilidade das células probióticas ao longo da vida de prateleira do produto e que o interesse no uso do meio reduzido M3 em análises sensoriais é perfeitamente justificado pela qualidade do produto gerado com o mesmo.

\section{REFERÊNCIAS}

BATISTA, A. P. S. A. Chocolate: sua história e principais características. Tese de mestrado, Universidade de Brasília. 2008.

CHAN, E.S.; ZHANG, Z. Bioencapsulation by compression coating of probiotic bacteria for their protection in an acidic medium. Process Biochemistry, v. 40, p. 33463351, 2005.

LEE; K ; HEO, T Survival of Bifidobacterium longum immobilized in calcium alginate beads in simulated gastric juices and bile salt solution. Applied and Environmental Microbiology, v.66, n.2, p. 869-873, 2000.

MENG, X. C.; STANTON, C.; FITZGERALD, G. F.; DALY, C.; ROSS, R. P., Anhydrobiotics: the challenges of drying. Food Chemistry Food Chemistry,v. 106, Issue 4, 15 p. 14061416, 2008.

OUYANG, W; CHEN, H ; JONES, ML ; METZ, T HAQUE, T ; MARTONI; C; PRAKASH, S Artificial cell microcapsule for oral delivery of live bacterial cells for therapy: design, preparation and in-vitro characterization. J. Pharm. Pharm. Sci, v.7, n.3, p315-324, 2004.

\section{AGRADECIMENTOS}

Os autores agradecem à FAPEMIG pelos recursos fornecidos, e também ao $\mathrm{CNPq}$, à CAPES e ao MEC pelas bolsas fornecidas. 